Check for updates

1 Harvard Medical School, Boston, USA

2 University of Global Health Equity, Rwanda

3 Sierra Leone

4 Yunus Centre, Bangladesh

5 Global Health and Social Medicine, Harvard Medical School, Boston, USA

6 Division of Global Health Equity, Brigham and Women's Hospital, USA

7 Partners In Health, USA

8 Seed Global Health, USA

9 Program in Global Public Policy and Social Change, Harvard Medical School, Boston, USA

10 Division of Pulmonary and Critical Care Medicine, Massachusetts General Hospital, USA

Correspondence to: $\mathrm{V}$ Kerry vkerry@seedglobalhealth.org Cite this as: BMJ 2021;374:n1837 http://dx.doi.org/10.1136/bmj.n1837 Published: 3 August 2021

\section{Intellectual property waiver for covid-19 vaccines will advance global health equity}

Parsa Erfani and colleagues argue that a temporary intellectual property waiver for covid-19 vaccines
is vital to increase supply, achieve global herd immunity, and advance global health equity

Parsa Erfani, ${ }^{1,2}$ Agnes Binagwaho, ${ }^{2}$ Mohamed Juldeh Jalloh, ${ }^{3}$ Muhammad Yunus, ${ }^{4}$ Paul Farmer, ${ }^{5,7}$ Vanessa Kerry 8,10

By late June $2021,46 \%$ of people in high income countries had received at least one dose of the covid-19 vaccine compared with $20 \%$ in middle income countries and only $0.9 \%$ in low income countries. ${ }^{1}$ This inequity has been driven by a global political economy that has permitted some countries to purchase more vaccine than they require while others have very limited supplies. Canada, for example, with a gross domestic product (GDP) of $\$ 46$ 000 ( $€_{32}$ ooo; $€_{39}$ ooo) per head has vaccines for $434 \%$ of its population, whereas Jordan, which has twice the incidence of covid-19 and a GDP of $\$ 4400$ per head, has secured doses for only $6 \%$ of its people. ${ }^{2}$ As covid-19 variants are already showing some ability to evade the current vaccines, it is evident that without global vaccine equity and immunity, our efforts against covid-19 are in jeopardy.

Equitable vaccine distribution to the world's highest risk populations requires a multipronged approach that includes vaccine development and approval; scaling manufacturing; streamlining shipment, storage, and distribution; and building vaccine confidence. International collaborations have helped tackle several of these fundamentals. However, the global community remains deeply divided on how to overcome the scarcity of supply. Pharmaceutical trade associations claim that supply is not a problem as manufacturers can supposedly provide 10 billion doses by the end of 2021. ${ }^{3}$ But as suppliers consistently fall short in achieving manufacturing targets, production is clearly a bottleneck to global vaccination. ${ }^{3}$ Indeed, at the current global vaccination rate, it will take years to achieve the needed level of global immunity. ${ }^{4}$

The barrier to adequate vaccine supply today is not lack of vaccine options, nor even theoretical production capacity; the problem is the intellectual property (IP) protection governing production and access to vaccines-and ultimately, the political and moral will to waive these protections in a time of global crisis. Without such liberty, there will not be enough vaccine fast enough to prevent the spread of variants, the avoidable deaths, and the continued choking of low and middle income countries (LMICs) through poor health.

\section{Beyond donor based models of global vaccine equity}

As covid-19 became a pandemic, global efforts emerged to help ensure vaccines would be delivered across the globe to the highest risk populations. One of the first was Covax, a risk sharing mechanism in which countries, tiered by means, contribute to collectively source and equitably distribute vaccines globally. The effort, however laudable in intent, has been undercut by vaccine scarcity and underfunding. Covax aims to vaccinate $20 \%$ of the population in 92 low and middle income countries by the end of 2021. At the end of April, however, it had shipped only one fifth of its projected estimates and lacked critical resources for distribution. ${ }^{3}$

LMICs are wary about participating in well worn dynamics of global health aid. Instead, they are mobilising to overcome the fundamental paucity of available vaccines by challenging established global IP rules. At issue is the 1995 Trade Related Aspects of Intellectual Property Rights (TRIPS) Agreement, which established minimum protection standards for IP-including patents, industrial designs, trade secrets, and copyright-that all 164 members of the World Trade Organization (WTO) must respect. ${ }^{5}$ Subsequent rulings (such as the Doha declaration) have strived to clarify safeguards on patents, including compulsory licensing, which allows governments to license patents to a third party without consent (table 1). ${ }^{6}$ Today, these rules provide strong IP protection for vaccine technologies and affect the quantity and location of vaccine production and availability. 
Table 1 | Licensing of intellectual property

Licence

Voluntary licence

Compulsory licence

\section{Definition}

Issued by the IP holder to a third party to produce the IP protected good. The licence usually sets quality requirements, establishes payment, and defines the markets in which the licensee can sell the product

Issued by a national government to a third party to produce a patented good without the patent holder's permission. The patent owner must still be "paid adequate remuneration" (adequate not defined). Compulsory licences apply specifically to patents. Each licence must be considered on its individual merit (TRIPS Article 31a). ${ }^{5}$ Blanket licences cannot be granted for a technology that has several patents. Under normal circumstances, the government must have first tried to negotiate a voluntary licence with the patent holder. But during national emergencies, other circumstances of extreme urgency, or public non-commercial use, governments can pursue compulsory licensing directly (TRIPS Article 31b). ${ }^{5}$ Under certain compulsory licences, importation and exportation of the licensed good is restricted or includes bureaucratic hurdles (TRIPS Article 31f, Article 31bis). 56

Proposed intellectual property waiver

A waiver that allows WTO members to not enforce any IP for health products and technologies related to the prevention, containment, or treatment of covid-19 for the duration of the pandemic (circumstances justifying the waiver would be assessed after a minimum period to determine its termination). The waiver includes all IP rights, not just patents, and allows for expeditious importation and exportation of covid-19 medical goods

In October 2020, South Africa and India submitted a proposal to the WTO to temporarily waive certain provisions of the TRIPS agreement for covid-19 health products and technologies. The waiver would prevent companies that hold the IP for covid-19 vaccines from blocking vaccine production elsewhere on the grounds of IP and allow countries to produce covid-19 medical goods locally and import or export them expeditiously (table 1). Although the proposed IP waiver is supported by over 100 countries, WTO has not reached a consensus on the proposal because of opposition and filibustering by several high income countries, including the UK, Germany, and Japan.

Waiver opponents argue that the limited capacity of LMICs to produce complex covid-19 vaccines safely is the true barrier to global production, not IP. They suggest that the TRIPS waiver would penalise drug companies, stifle biomedical innovation, and deter future investments in research and development-in sum, that it would reduce returns on investment and dismantle an IP system that provided the goods needed to end the pandemic. Others are concerned that an IP waiver would fuel supply chain bottlenecks for raw materials and undermine ongoing production. Moreover, policy makers argue that a waiver is unnecessary as company driven voluntary licensing -in which companies decide when and how to license their technologies-and existing TRIPS flexibilities (such as country determined compulsory licensing) should suffice in establishing production in LMICs (table 1). They suggest that waiving IP for covid-19 vaccines would provide no meaningful progress, but the data do not support this.

\section{What effect would a waiver have?}

Contrary to detractors' concerns about the possible effect of a temporary TRIPS waiver, global health analyses suggest that it will be vital to equitable and effective action against covid-19. LMIC's manufacturing capabilities have been underestimated, even though several LMICs have the scientific and manufacturing capacity to produce complex covid-19 vaccines. India, Egypt, and Thailand are already manufacturing viral vector or mRNA-based covid-19 vaccines, ${ }^{8-10}$ and vaccine production lines could be established within months in some other LMICs, ${ }^{11}$ offering substantial benefit in a pandemic that will last years. ${ }^{11}$

Companies in India and China have already developed complex pneumococcal and hepatitis $B$ recombinant vaccines, challenging existing vaccine monopolies. ${ }^{12}$ The World Health Organization launched an mRNA technology transfer hub in April 2021 to provide the logistical, training, and know-how support needed for manufacturers in LMICs to repurpose or expand existing manufacturing capacity to produce covid-19 vaccines and to help navigate accessing IP rights for the technology. ${ }^{13}$ Twenty five respondents from LMICs expressed interest, and South Africa was selected as the first hub, with plans to start producing the vaccine through the Biovac Institute in the coming months. ${ }^{14}$

Removing IP barriers through the waiver will facilitate these efforts, more rapidly enable future hubs, engage a greater number of manufacturers, and ultimately yield more doses faster. Moreover, as the waiver facilitates vaccine production, demand for raw materials and active ingredients will increase. Coupled with pre-emptive planning to anticipate and expand raw material production, the waiver-which encompasses the IP of all covid-19 vaccine-related technology - can offer a path to overcome bottlenecks and expand production of necessary vaccine materials.

\section{Current licensing mechanisms inadequate}

Voluntary licences have not and will not keep pace with public health demand. Since companies determine the terms of voluntary licences, they are often granted to LMICs that can afford them, leaving out poorer regions. ${ }^{10}$ For example, in South Asia, AstraZeneca has voluntarily licensed its vaccine to the Serum Institute of India, even though the region has multiple capable vaccine manufacturers. ${ }^{9}$ Many covid-19 vaccine developers have not taken steps towards licensing their technologies, simply because there is limited financial incentive to do so. ${ }^{11}$ To date, none have shared IP protected vaccine information with the WHO Covid-19 Technology Access Pool (C-TAP) established last year. ${ }^{15}$ Relying on the moral compass of companies that answer to shareholders to voluntarily license their technologies will have limited effect on vaccine equity. Their market is driven by profit margins, not public health.

Compulsory licensing by LMICs will also be insufficient in rapidly expanding vaccine production, as each patent licence must be negotiated separately by each country and for each product based on its own merit. From 1995 to 2016, 108 compulsory licences were attempted and only 53 were approved. ${ }^{6}$ The case-by-case approach is slow and not suitable for a global crisis that requires swift action. In addition, TRIPS requires compulsory licences to be used 
predominantly for domestic supply, limiting exports of the licensed goods to nearby low income countries without production capacity. ${ }^{5}$

Although a "special” compulsory licence system was agreed in the Doha declaration to allow for expeditious exportation and importation (formalised as the article 31 bis amendment to TRIPS in 2017), the provision is limited by cumbersome logistical procedures and has been rarely used. ${ }^{16}$ Governments may also be hesitant to pursue compulsory licences as high income countries have previously bullied them for doing so. Since India first used compulsory licensing for sorafenib tosylate in 2012 (reducing the cancer drug's price by $97 \%$ ), the US has consistently pressured the country not to use further compulsory licences. ${ }^{17}$ During this pandemic, Gilead sued the Russian government for issuing a compulsory licence for remdesivir. ${ }^{18}$

Furthermore, while compulsory licences are primarily for patents, covid-19 vaccines often have other types of IP, including trade secrets, that are integral for production. ${ }^{19}$ The emergency TRIPS waiver removes all IP as a barrier to starting production (not just patents) and negates the prolonged time, inconsistency, frequent failure, and political pressure that accompany voluntary licensing and compulsory licensing efforts. It also provides an expeditious path for new suppliers to import and export vaccines to countries in need without bureaucratic limitations.

Finally, there is no compelling evidence that the proposed TRIPS waiver would dismantle the IP system and its innovation incentives. The waiver is restricted to covid-19 related goods and is time limited, helping to protect future innovation. It would, however, reduce profit margins on current covid-19 vaccines. With substantial earnings in the first quarter of 2021, many drug companies have already recouped their research and development costs for covid-19 vaccines. ${ }^{20}$ However, they have not been the sole investors in vaccine development, and they should not be the only ones to profit. Most vaccines received a substantial portion of their direct funding from governments and not-for-profit organisations-and for some, such as Moderna and Novavax, nearly all. ${ }^{21}$ Decades of publicly funded research have laid the groundwork for current innovations in the background technologies used for vaccines. ${ }^{22}$ Given that companies were granted upfront risk protection for covid-19 vaccine research and development, a waiver that advances global public health but reduces vaccine profits in a global crisis is reasonable.

\section{Knowledge transfer}

An IP waiver for covid-19 vaccines is integral to boosting vaccine supply, breaking vaccine monopolies, and making vaccines more affordable in LMICs. It is, however, only a first, but necessary, step. Originator companies must transfer vaccine technology and share know-how with C-TAP, transfer hubs, or individual manufacturers to help suppliers begin production. ${ }^{23}$ In addition, governments must leverage domestic law, private sector incentives, and contract terms with pharmaceutical companies to compel companies to cooperate with such transfers. ${ }^{24}$ If necessary, governments can require technology transfers in exchange for continuing enterprise in a country or avoiding penalties.

Politicians and leaders are at a critical juncture: they will either take the necessary steps to make vaccine technology available to scale production, stimulate global collaboration, and create a path to equity or they will protect a hierarchical system based on an economic bottom line. The former will not only build a vaccination trajectory that puts equal value on the lives of the rich and the poor, but will also help stem the pandemic's relentless momentum and quell the emergence of variants.
We are in the middle of one of the largest vaccination efforts in human history. We cannot rely on companies to thread the needle of corporate social and moral responsibility with shareholder and stock value returns nor expect impacted governments to endure lengthy bureaucratic licensing processes in this time of crisis. It will be a legacy of apathy and unnecessary death. As the human impact of the proposed IP waiver becomes clear, consensus behind it is growing. Countries that previously opposed the waiver-such as the US and Brazil-now support written text based negotiations. ${ }^{7}$ Opposing countries must stop blocking the waiver, engage in transparent text negotiations, and commit to reaching consensus swiftly.

The longer states stall, the more people die needlessly. Covid-19 has repeatedly shown that people without access to resources such as strong health systems, health workers, medicines, and vaccines will preferentially fall ill and die. For too long, this cycle has been “other people's” problem. It is not. It is our problem.

\section{Key messages}

- Global covid-19 vaccine inequity is driven by accumulation of vaccines by high income countries and restricted vaccine production by a small number of manufacturers

- Donor based approaches to global vaccine equity will continue to yield limited results

- Sharing intellectual property and technological know-how is essential to help rapidly expand covid-19 vaccine production

- Countries must agree on a temporary intellectual waiver for covid-19 goods to achieve global herd immunity and advance global health equity

Contributors and sources: This article is based on analysis of current covid-19 data, international agreements, and their prior execution. PE and VK were involved in the conceptualisation, data curation and original drafting of the manuscript. VK is the guarantor. AB, MJJ, MY, and PF were involved in writing review and editing. The authors have decades of experience advancing global health equity as leaders of governments (Sierra Leone), universities (University of Global Health Equity), non-profit organisations (Partners In Health, Seed Global Health), and community development initiatives (Grameen Bank).

Competing interests: We have read and understood BMJ policy on declaration of interests and have no interests to declare.

Provenance and peer review: Not commissioned; externally peer reviewed.

Our World in Data. Coronavirus (covid-19) vaccinations-statistics and research. 2021. https://ourworldindata.org/covid-vaccinations

2 Duke Global Health Innovation Center. Launch and scale speedometer. Duke University, 2021. https://launchandscalefaster.org/COVID-19\#Commitments

Rizvi Z. Not enough: six reasons why covid-19 vaccine manufacturing must be rapidly scaled-up. Public Citizen 2021. https://www.citizen.org/article/not-enough-six-reasons-why-covid-19-vaccinemanufacturing-must-be-rapidly-scaled-up/\#_ftn11

Covid-19 vaccine tracker. Bloomberg, 2021. https://www.bloomberg.com/graphics/covid-vaccinetracker-global-distribution/

World Trade Organization. TRIPS agreement. 1994. https://www.wto.org/english/docs_e/legal_e/27-trips_02_e.htm

6 Son KB, Lee TJ. Compulsory licensing of pharmaceuticals reconsidered: Current situation and implications for access to medicines. Glob Public Health 2018;13:1430-40. doi: 10.1080/17441692.2017.1407811 pmid: 29183271

7 Green A. WTO council offers hope for TRIPS vaccine proposal. Devex 2021 Jun 10. https:/www.devex.com/news/wto-council-offers-hope-for-trips-vaccine-proposal-100125

8 Edward-Ekpu U. Egypt races to produce critically-needed covid-19 vaccines. Quartz Africa 2021 Jun 11. https://qz.com/africa/2019420/egypt-races-to-produce-critically-needed-covid-19-vaccines/

9 Vaccine patents, global equity and how to vaccinate the world. WBUR, 24 Mar 2021. https://www.wbur.org/onpoint/2021/03/24/how-to-equitably-vaccinate-the-world

10 Irwin A. What it will take to vaccinate the world against covid-19. Nature 2021;592:176-8.

11 Morten C, Herder M. We can't trust big pharma to make enough vaccines. Nation 2021 May 31. https://www.thenation.com/article/world/covid-vaccines-pharma/

12 Médecins Sans Frontières. WTO covid-19 TRIPS waiver proposal. 2020. https://msfaccess.org/sites/default/files/2020-12/MSF-AC_COVID_IP_TRIPSWaiverMythsRealities_Dec2020.pdf 
13 WHO. WHO supporting South African consortium to establish first covid mRNA vaccine technology transfer hub. 2021 https://www.who.int/news/item/21-06-2021-who-supporting-south-africanconsortium-to-establish-first-covid-mrna-vaccine-technology-transfer-hub

14 Jerving S. Biovac Institute to be first African company to produce mRNA vaccines. Devex 2021 Jul 21. https://www.devex.com/news/biovac-institute-to-be-first-african-company-to-producemrna-vaccines-100432

15 Safi M. WHO platform for pharmaceutical firms unused since pandemic began. Guardian 2021 Jan 22. https://www.theguardian.com/world/2021/jan/22/who-platform-for-pharmaceutical-firmsunused-since-pandemic-began

16 Garrison C. Never say never-why the high income countries that opted-out from the Art. 31bis WTO TRIPS system must urgently reconsider their decision in the face of the covid-19 pandemic Medicines Law \& Policy 2020 Apr 8. https://medicineslawandpolicy.org/2020/04/never-saynever-why-the-high-income-countries-that-opted-out-from-the-art-31bis-wto-trips-system-musturgently-reconsider-their-decision-in-the-face-of-the-covid-19-pandemic/

17 Médecins Sans Frontières. A timeline of US attacks on India's patent law and generic competition. 2015. https://msfaccess.org/sites/default/files/2018-10/IP_Timeline_US\%20pressure\%20on\%20India_Sep\%202014_0.pdf

18 Gilead sues Russia: private company challenges a country's right to protect public health. Make Medicines Affordable, 2021. https://makemedicinesaffordable.org/gilead-sues-russia-privatecompany-challenges-a-countrys-right-to-protect-public-health/

19 Contreras J. US Support for a WTO waiver of covid-19 intellectual property - what does it mean? Bill of Health, 2021. https://blog.petrieflom.law.harvard.edu/2021/05/07/wto-waiver-intellectualproperty-covid/

20 Buchholz K. Covid-19 vaccines lift pharma company profits. Statista 2021. https://www.statista.com/chart/24829/net-income-profit-pharma-companies/

21 Covid vaccines: Will drug companies make bumper profits? BBC News 2020 Apr 22. https://www.bbc.com/news/business-55170756

22 Cross S, Rho Y, Reddy H, etal. Who funded the research behind the Oxford-AstraZeneca COVID-19 vaccine? Approximating the funding to the University of Oxford for the research and development of the ChAdOx vaccine technology. [Preprint.] medRxiv 2021;2021.04.08.21255103. doi: 10.1101/2021.04.08.21255103

23 Gonsalves G, Yamey G. The covid-19 vaccine patent waiver: a crucial step towards a "people's vaccine."BMJ2021;373:n1249. doi: 10.1136/bmj.n1249. pmid: 34001498

24 Kapczynski A, Ravinthiran J. How to vaccinate the world, part 2. LPE Project 2021. https://peproject.org/blog/how-to-vaccinate-the-world-part-2

This article is made freely available for use in accordance with BMJ's website terms and conditions for the duration of the covid-19 pandemic or until otherwise determined by BMJ. You may use, download and print the article for any lawful, non-commercial purpose (including text and data mining) provided that all copyright notices and trade marks are retained. 